\title{
Dengue Hemorrhagic Fever with Discolored Leg Syndrome in a Neonate: Correspondence
}

\author{
J. B. Ghosh
}

Received: 30 September 2014 / Accepted: 5 November 2014 / Published online: 23 November 2014

(C) Dr. K C Chaudhuri Foundation 2014

To the Editor: I have read with interest the article "Dengue Hemorrhagic Fever with Discolored Leg Syndrome in a Neonate" published recently by Vijoo et al. [1]. The authors have excluded the possibility of late onset sepsis with disseminated intravascular coagulation (DIC) by presence of negative blood culture and C-reactive protein (CRP). Some of the laboratory markers like thrombocytopenia, prolonged prothrombin and activated partial thromboplastin time, deranged liver function may suggest DIC. Blood level of fibrinogen, fibrinogen degradation products, D-Dimer value should have been done to exclude DIC which can occur as a complication of dengue hemorrhagic fever (DHF) [2]. DIC can explain the abnormal hematological parameter and skin manifestation of the index case. The authors have excluded purpura fulminans by well maintained peripheral pulse and normal Doppler study. Discoloured Leg Syndrome (DLS) is defined as an even or patchy red, blue or purple discolouration of leg(s) and/or leg petichae with or without swelling. Till date its pathophysiology is unknown but assumed to be a vasomotor reaction. It has no confirmatory diagnostic test. Kammeren et al. in their study comprising of large number of cases found that DLS occurs mostly following vaccination [3]. History of prior vaccination which is commonly available in DLS was lacking in the present case. I think DLS may be considered as an exclusion diagnosis. So in this index case possibility of DIC also should have been excluded by few more studies as have been mentioned above.

Conflict of Interest None.

Source of Funding None.

\section{References}

1. Vijoo M, Raja R, Venkatesh C, Ramkumar U, Soundararajn P. Dengue hemorrhagic fever with discolored leg syndrome in a neonate. Indian J Pediatr. 2014;81:833-4.

2. Scott JP, Raffini LJ, Montgomery RR. Disseminated intravascular coagulation. In: Kliegman RM, Behrman RE, Schor NF, Stanton BF, editors. Nelson textbook of paediatrics. 19th ed. Philadelphia: Elsevier Saunders; 2011. p. 1713-4.

3. Kemmeren JM, Vermmer-de Bondt PE, Van der Mass NA. Discoloured leg syndrome after vaccination-descriptive epidemiology. Eur J Pediatr. 2009;168:43-50.

\footnotetext{
J. B. Ghosh

Department of Pediatrics, I.P.G.M.E\&R, Kolkata, India

J. B. Ghosh $(\bowtie)$

Ushashi Housing Society, 245 Vivekananda Road, Kolkata 700006,

India

e-mail: jbghosh@yahoo.com
} 